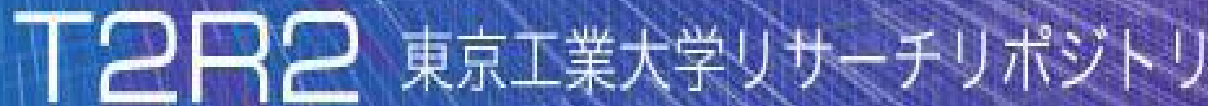

\section{Tokyo Tech Research Repository}

\section{論文 /著書情報 \\ Article /Book Information}

\begin{tabular}{|c|c|}
\hline Title & International Distance Education at CRADLE and Natural Disasters \\
\hline Author & Akinori Nishihara \\
\hline Journal/Book name & IEEE Region 10 Humanitarian Technology Conference 2013, , , \\
\hline Issue date & 2013, 8 \\
\hline DOI & http://dx.doi.org/10.1109/R10-HTC.2013.6669055 \\
\hline URL & http://www.ieee.org/ndex.html \\
\hline Copyright & $\begin{array}{l}\text { (c) } 2013 \text { IEEE. Personal use of this material is permitted. Permission } \\
\text { from IEEE must be obtained for all other users, including } \\
\text { reprinting kepublishing this material for advertising or promotional } \\
\text { purposes, creating new collective works for resale or redistribution to } \\
\text { servers or lists, or reuse of any copyrighted components of this work in } \\
\text { other works. }\end{array}$ \\
\hline Note & $\begin{array}{l}\text { このファイルは著者 (最終) 版です。 } \\
\text { This file is author (final) version. }\end{array}$ \\
\hline
\end{tabular}




\title{
International Distance Education at CRADLE and Natural Disasters
}

\author{
Akinori Nishihara \\ Center for Research and Development of Educational Technology \\ Tokyo Institute of Technology \\ Tokyo, 152-8552 Japan \\ http://www.nh.cradle.titech.ac.jp
}

\begin{abstract}
CRADLE (Center for Research and Development of Educational Technology), Tokyo Tech (Tokyo Institute of Technology) has been conducting international distance education activities since 2002 using both satellite and Internet. Formal graduate level courses have been exchanged with partner institutions in Thailand and the Philippines. We also have experimental lecture exchange. In many cases the network bandwidth is limited to several hundred kbps to several Mbps, but we are trying to test HD (High-Definition) video transmission with about 30Mbps when the situations allow. It is found that using HD video transmission, presence, immediacy, and satisfaction increase. We experienced several severe natural disasters during the last decade of our project. We report how those natural disasters affected our distance education activities, and how we overcame them.
\end{abstract}

\section{INTRODUCTION}

Information and communication technology can suitably be used to overcome not only physical distance but also mental distance between learners and teachers as well as among learners. Distance education utilizes information and communication technology to bridge the people of different places separated thousands of kilometers [1]. Our distance education with Asian countries uses either satellite or Internet. High technology may be fragile to some troubles; power failure is a typical example; we can do almost nothing without electrical power. Obviously natural disasters such as earthquakes and tsunamis seriously affect our lives, and our distance education activities were also influenced by earthquakes, floods, etc.

\section{INTERNATIONAL DistANCE EDUCATION AT CRADLE}

CRADLE (Center for Research and Development of Educational Technology), Tokyo Tech (Tokyo Institute of Technology), set up the ANDES (Academic Network for Distance Education by Satellite) system in 1996, for the use in lecture deliveries via commercial communication satellite. The ANDES system has been used for lecture exchange with Hitotsubashi University, famous national university in social science, open lecture delivery to workplace engineers, and high-school university collaboration in which undergraduate lecture courses are transmitted to high-school students all over Japan who are interested in science and technology. Since 2002 some of the courses taught in English in the International Graduate Program are transmitted to Thailand using ANDES system[2]. Later we used a branch line of JGN2 (Japan Gigabit Network 2), an ultrahigh-speed testbed networks for research and development collaboration among industry, academia, and the government[3].
In 2007 we established a new graduate program named TAIST (Thailand Advance Institute of Science and Technology). TAIST is based on the idea of collaboration among Tokyo Tech, NSTDA (National Science and Technology Development Agency) and partner universities to develop human resources. Now there are 3 master programs going on; Automotive Engineering, Information and Communication Technology for Embedded Systems, and Advanced and Sustainable Environmental Engineering. Each program has 30 students every year. Tokyo Tech is responsible for giving lectures. Some courses are taught as 1-week intensive face-to-face lectures, and others are delivered from either Ookayama or Suzukakedai campuses in Japan as distance education[4]. To manage the international distance education and to promote and research collaboration, Tokyo Tech Thailand Office was established in 2002 in the NSTDA building in the TSP (Thailand Science Park).

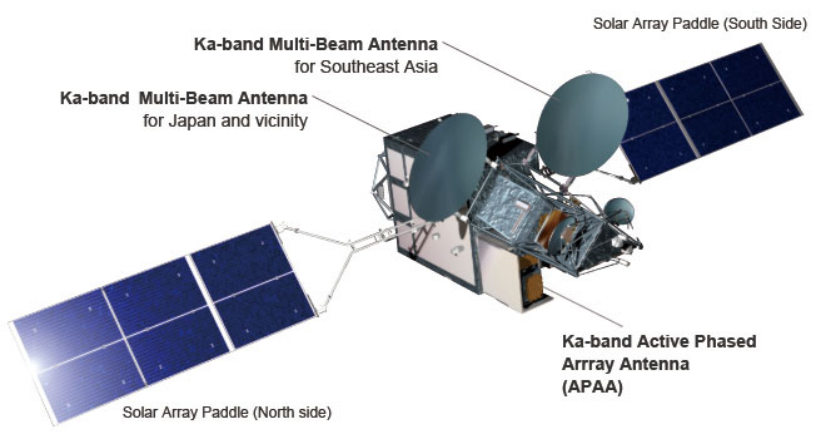

Fig. 1. KIZUNA (WINDS)

http://www.jaxa.jp/countdown/f14/overview/kizuna_e.html

In February 2008 WINDS (Wideband InterNetworking engineering test and Demonstration Satellite) was launched by JAXA (Japan Aerospace Exploration Agency) and NICT (National Institute of Information and Communication Technology). The satellite is in geostationary orbit at 143 degrees E, and named "KIZUNA", which means bond or link in Japanese (Fig. 1). MIC (Ministry of Internal affairs and Communications) called for proposals of its application experiments before the launch, and 53 experiments (27 from Japan and others from abroad) were accepted. CRADLE was a member of a team with Chulalongkorn University, Hokkaido University, National Broadcast and Telecommunication Commission, and University of the Philippines Diliman (Fig. 2). With the help of JAXA and NICT we conducted 5-year experiment to fully utilize 
WINDS' wide bandwidth and compatibility with Internet. HD (high-definition) videos of lectures have been transmitted with seamless connection of satellite multicast and IP multicast in terrestrial academic networks. We confirmed that HD video transmission enables effective distance education, if not comparable to face-to-face lectures.

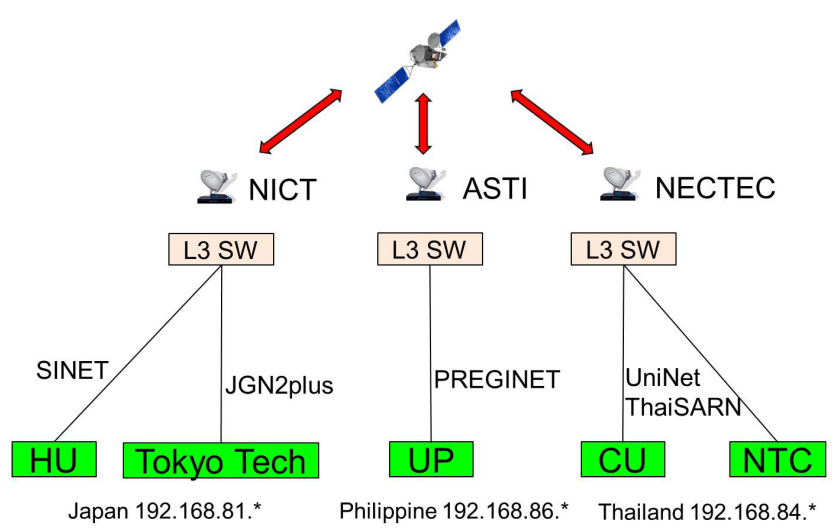

Fig. 2. KIZUNA Experiment Network Structure

\section{NATURAl DisASTERS}

We experienced 4 big natural disasters in the last 12 years of our international distance education activities. All 4 were, of course, terribly serious to the local people, but our distance education activities were also affected.

\section{A. Hengchun Earthquake in 2006}

The 2006 Hengchun earthquake occurred on Tuesday, 26 December, 2006 at 12:25 UTC (20:25 local time). That earthquake damaged several submarine communications cables and catastrophically disrupted international telecommunications including telephone and Internet services in many Asian countries. At that time our lecture delivery to AIT (Asian Institute of Technology) was using JGN2, which passes through one of these submarine cables, which was also damaged. Nobody knew how long it would take for the recovery. Fortunately that was during the winter break, and the next lecture was scheduled about 2 weeks later. So we decided to reserve a commercial satellite link, which had been used for the previous 4 years in that project and was (and still is) used for other lecture delivery projects (see Fig. 3). Although we reserved the satellite link for 3 times in 3 weeks, we only used once. The JGN2 connection was recovered in the middle of January, and we canceled the rest 2 reservations.

\section{B. Flood in the Philippines in 2011}

Typhoons Nesat and Nalgae attacked the Philippines in September 2011. The typhoon storm brought some of the worst flooding in decades to Metro Manila. The flood submerged Internet equipment and so the optical fiber connection was cut off between UP (University of the Philippines) and ASTI (Advanced Science and Technology Institute), where Ka band antenna for KIZUNA was installed. Even though e-mails were available, it took several months to replace optical fiber link and other equipment to transmit high data rate such as HD

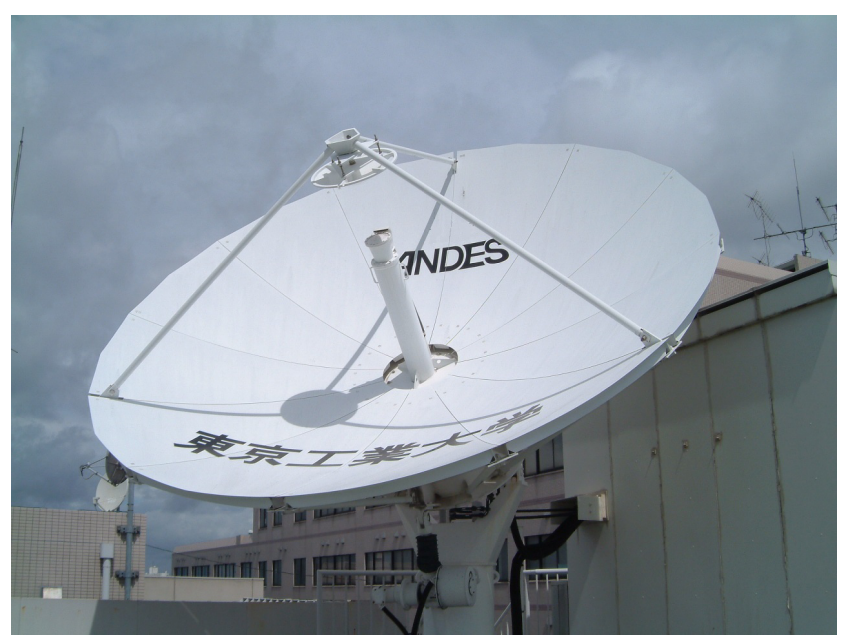

Fig. 3. 4.5m ANDES antenna

video, and it was April 2012 when we could restart WINDS Application Experiment with UP. During the time UP was absent, we asked ASTI staff to receive the satellite signals from CU and Tokyo Tech, although they could not transmit any signals because of lack of equipment like a HD video camera.

\section{Great East Japan Earthquake in 2011}

Great East Japan Earthquake occurred at 14:46 JST (05:46 UTC) on Friday, 11 March 2011. The earthquake triggered huge tsunami waves that reached heights of up to 40.5 meters in Miyako, Iwate Prefecture. Many other places in Iwate, Miyagi, and Fukushima Prefectures were also hit by more than 10-meter tsunami. The tsunami caused nuclear accidents, primarily the level 7 meltdowns at three reactors in the Fukushima Daiichi Nuclear Power Plant.

Cellular and fixed-line telephone services suffered disruptions in those areas. Many cellular phone base stations were broken or washed out, and cables were cut. Even if those facilities had remained safe, they could not function normally for long because blackouts and road damage made it impossible to recharge batteries or refuel emergency power generators.

Internet services were not so much affected in areas where basic infrastructure remained. People relied on the Internet and Twitter to collect information and to confirm safety of relatives and friends.

We had a regular series of experiments using KIZUNA every other Friday. On Friday, 11 March 2011, we were planning to have an experiment from 15:00 JST. The earthquake occurred only 14 minutes before, and at my office on the 8th floor a lot of documents fell down from the shelves as shown in Fig.4. We also had a blackout in our building (although almost all other parts of Tokyo Tech campus were all right), and the experiment of that day was canceled. Public transportation was stopped and more than 100,000 people in Tokyo could not go home on that day.

JAXA decided to use KIZUNA for support of affected areas. NICT set up a HD teleconference system using the 


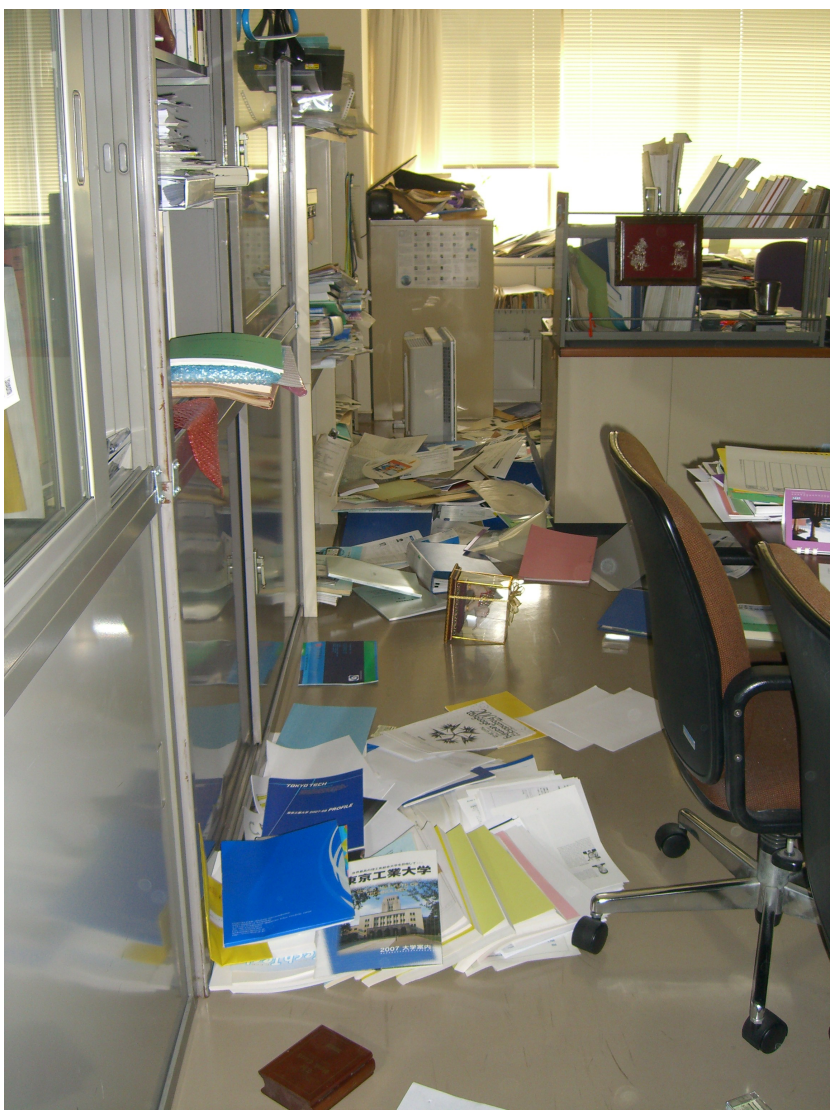

Fig. 4. My office in Tokyo at 14:50 on 11 March 2011

KIZUNA between Kesennuma City (Fire Department Headquarters), Miyagi Prefecture, and the Tokyo Fire Department. HD teleconferences, which enable real-time information sharing that is necessary for support activities in disaster-stricken areas, were conducted from March 15. JAXA installed a movable ground antenna for KIZUNA at the Iwate Prefectural Office (Disaster measures headquarters) and in Kamaishi City (Local disaster measures office). Broadband lines were connected on March 20, and HD teleconference systems, IP telephones, and radio LANs became available. Those systems were well utilized till April 24 when terrestrial communication channels resumed. This utilization of KIZUNA is in line with its original aims, which are anytime anywhere communications or disaster-resistant and far-reaching communications.

All the WINDS Application Experiments using KIZUNA were suspended during that time, and we just hoped fast recovery of those areas. We could restart the experiments from May 2011. The experiment continued to March 2013 (total 5 years), and we investigated technical issues related to multicast distribution of HD videos and lecture styles suitable for distance education (Fig.5).

\section{Flood in Thailand in 2011}

During 2011 monsoon season in Thailand, overwhelming flooding occurred. Rainfall started in June, and the number of Typhoons were more than usual and came early (June). The flooding affected millions of houses, crops, and infrastructure. The flood slowly went southward, and reached TSP in the

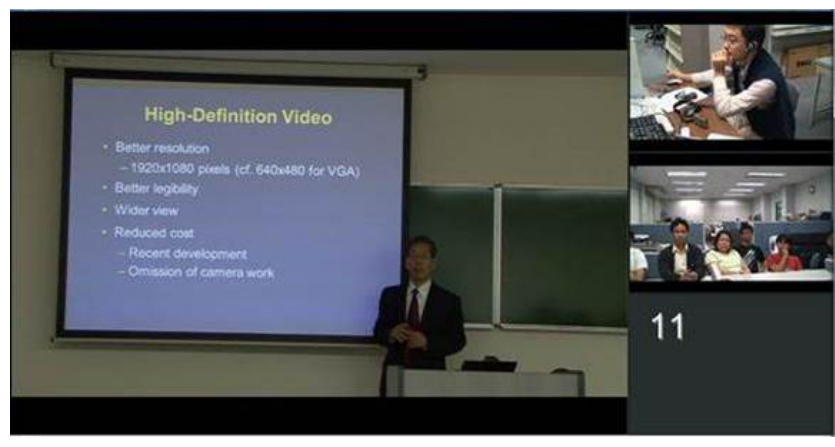

Fig. 5. Lecture transmitted by KIZUNA

middle of October. TSP had no choice but to close all the activities (see Fig. 6).

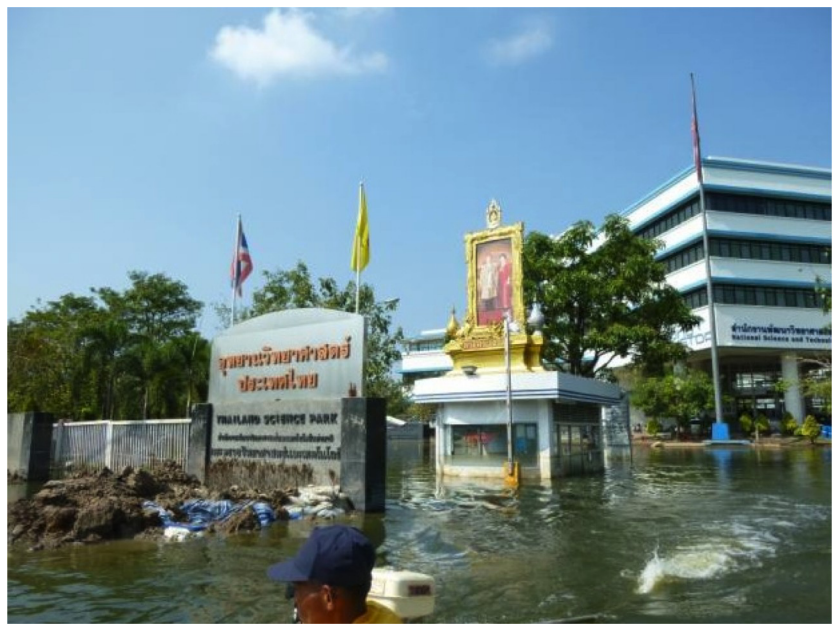

Fig. 6. NSTDA in the end of October

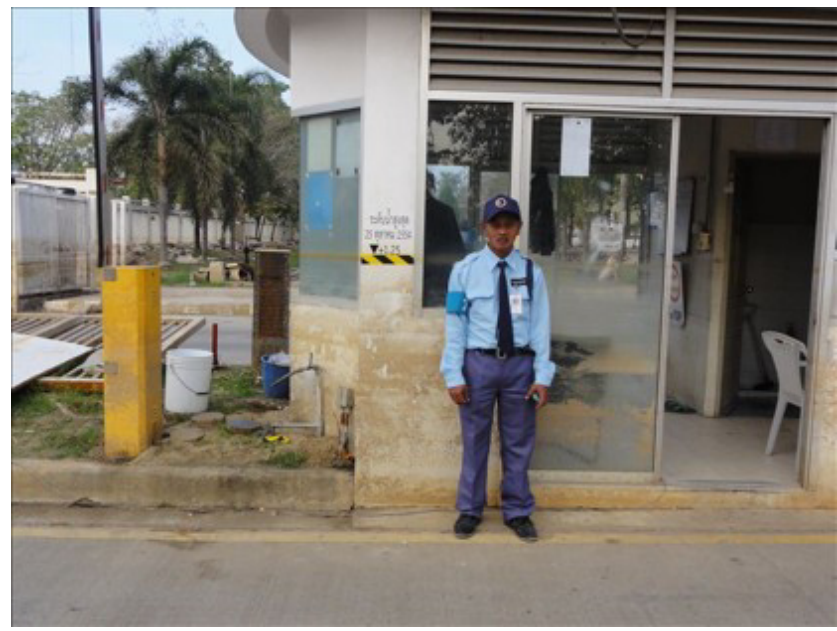

Fig. 7. NSTDA in early December

Several weeks later the water level gradually went down as it had come. Luckily NSTDA buildings have higher ground floor level than outside ground surface, and so the inside of buildings was dry. As seen in Fig. 7, at the main entrance of 
NSTDA the water level went up to the shoulder of a guard.

Even though NSTDA buildings themselves were all right, there were transportation problems and some staff and students could not come. Thus we could restart our TAIST courses in the middle of December.

This delay caused a lot of trouble in arranging Tokyo Tech faculty members as TAIST lecturers. They have primary duties at Tokyo Tech and so it is not so easy to reschedule their 1week visit to Bangkok for intensive lectures. Some changed the lecture mode from face-to-face lecture in Bangkok to distance education from Ookayama or Suzukakedai campus as shown in Fig. 8.

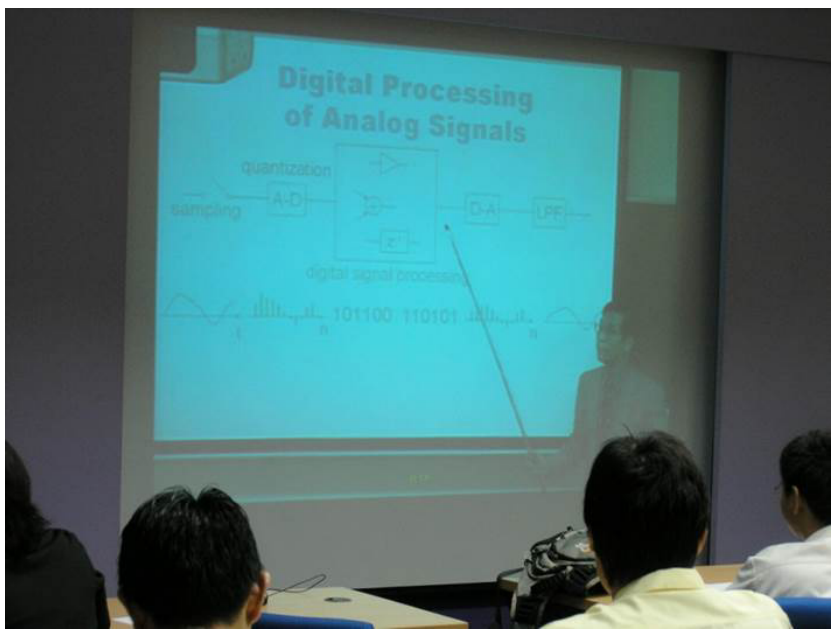

Fig. 8. Lecture taught from Tokyo

Although Chulalongkorn University located in central Bangkok was not submerged, they could not participate our KIZUNA experiment due to closure of NECTEC (National Electronics and Computer Technology Center) in NSTDA, where KIZUNA antenna was installed.

\section{E. Another Incident}

In November 2008 there were big political demonstrations in Thailand, especially in central Bangkok. TAIST campus is located in TSP in Pathum Thani, which is about $30 \mathrm{~km}$ north of central Bangkok, and so the situations in TSP were normal. Tokyo Tech faculty members staying there at that time gave lectures as usual. They were advised not to go to central Bangkok.

When People's Alliance for Democracy illegally occupied the Thailand main international airport (Suvarnabhumi) for about a week, Tokyo Tech members could not return to Japan. One came from U-Tapao international airport which is a military airport in Rayong province located about $140 \mathrm{~km}$ southeast of Bangkok and was used temporarily as a supplementary international gateway. Many airlines arranged special flights from and to U-Tapao to ferry stranded international passengers.

We dared not dispatch our faculty members in the following weeks. Several courses are then taught as distance education from Tokyo with the same schedule. This change of lecture mode was not a problem and went quite smoothly.

\section{F. Lessons Learned}

High technology is often vulnerable to natural disasters as mentioned above. Communications among family members, friends, and acquaintances are especially important during and after disasters, but telephone and internet communications are usually very limited. Technology itself should be improved to be more reliable, robust, disaster-resistant and flexible. Alternative means should be prepared for emergency usage. Users should also be well prepared to effectively share and utilize the technology which is available at that point of time. Public information should be prioritized, and private communications should be minimized.

\section{Lecture Styles For Distance EduCATION}

There are several lecture styles which can be used in distance education.

As in a traditional classroom, we can use a blackboard (or whiteboard) as in Fig. 9. This may be a simple and convenient method especially for instructors who are accustomed to a traditional way. This style works well if the video resolution is high enough even though the video camera is fixed. If the resolution is not enough, zooming a particular part will be necessary, and that needs human resources (to operate the camera) and often degrades students' satisfaction; they may not see what they want to see.

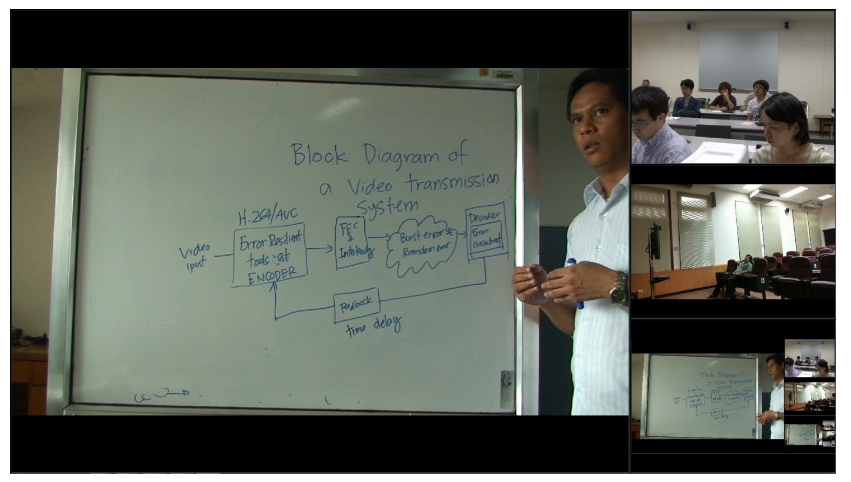

Fig. 9. Whiteboard-based Lecture

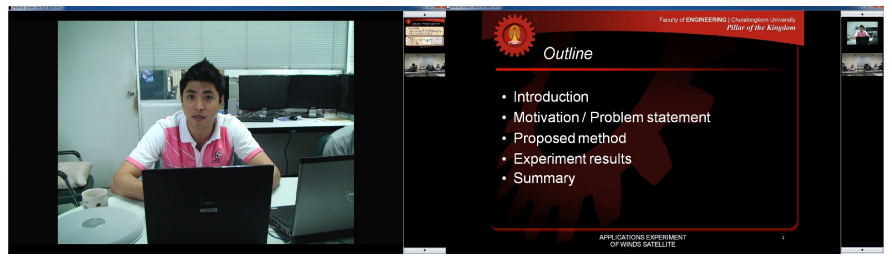

Fig. 10. PC Desktop-based Lecture

Recently many instructors use computer-based presentation tools in their lectures. It is not difficult to share the PC desktop image with remote students as shown in right hand side of Fig.10. Instructor's video can also be transmitted as in left had side of Fig.10. Students use either two displays at a time or switch over the two scenes using one display. In the latter case students may lose their concentration to some extent by switching operations. If plural students share a display, they might have different wishes for the choice of scenes. 
A simple variation of PC desktop-based style is to place a lecturer window over the PC desktop as in Fig.11. This is called a picture-in-picture style. In this case the lecturer window is usually small not to hide the slide contents, which often fosters a sense of isolation.

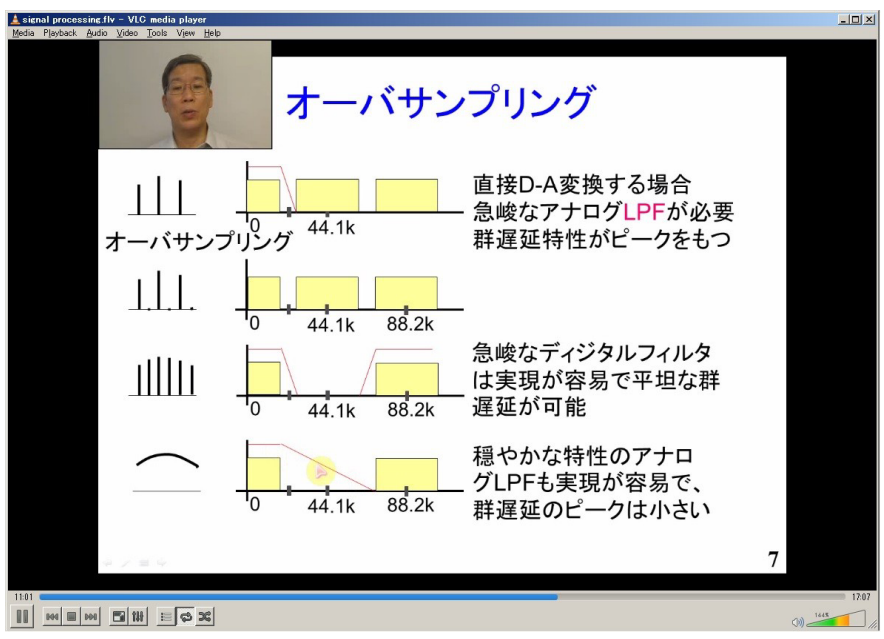

Fig. 11. Picture in picture Lecture

Another computer-based lecture is shown in Figs. 5 and 8, where the instructor uses either a projected screen or a large display to show his/her computer output and teach in front of the display.

Yet another computer-based lecture is to use chroma key, where a instructor is superimposed on a slide show as shown in Fig.12. This requires special equipment and a blue or green screen as background of the instructor. The instructor needs some getting used to it, because he/she has to point a blank object before superimposing the slide. Chroma key creates a similar appearance as TV weather forecasts.

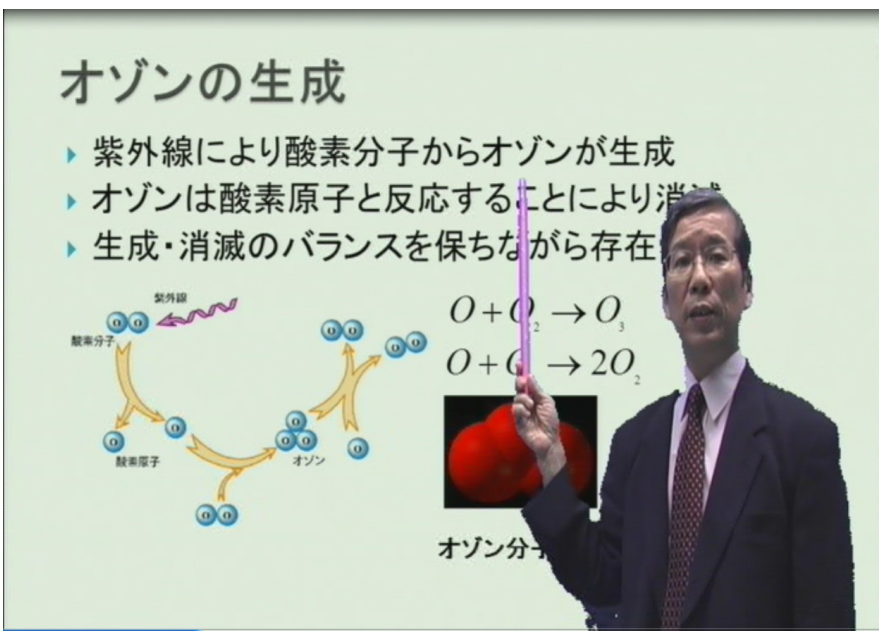

Fig. 12. Chroma key-based Lecture

Among these lecture styles, PC desktop style (including picture in picture) usually has less movement of the instructor, and so the students don't feel so much presence of the instructor. Other styles include more movement of the instructor, which is closer to traditional classrooms, and students feel more presence and immediacy. In those cases the lecturer should use both non-verbal immediacy such as smiling, gesturing, eye contact, etc. and verbal immediacy such as using humor, asking questions, etc. [6]. Lecturers have to try to maximize those non-verbal and verbal immediacy, which increases students' satisfaction.

To better convey non-verbal immediacy of the lecturer we had better use high quality video such as HDTV, $4 \mathrm{~K}$, or even $8 \mathrm{~K}$ formats. Of course there is a trade-off between video quality and data rate, and so depending of the situations such as network bandwidth and equipment we have to choose a proper resolution of video. When multiple locations are connected, we had better use multicast to avoid duplicate transmission.

\section{CONCLUSIONS}

Natural disasters can not be avoided, and nobody knows when and what types of disaster attacks us next and in which level. High technology may be weak to such natural disasters, but it is technology that can be fully utilized to mitigate and overcome disasters. Especially information and communication technology is very important to keep our safety and security during and immediately after natural disasters. Alternative means should be prepared, or at least considered for emergency usage. As citizens we have to be prepared to natural disasters, and as engineers we have to develop disaster-resistant technologies. A recovery manual from natural disasters would be helpful.

\section{ACKNOWLEDGMENT}

The author is indebted to members of CRADLE and GSIC (Global Scientific and Information Center) in Tokyo Tech for their supports, and colleagues in partner institutions in Thailand and the Philippines for their cooperation.

\section{REFERENCES}

[1] M. Moore and G. Kearsley, Distance Education: A Systems View of Online Learning, Wardsworth, 2011.

[2] S. Yamaguchi, H. Niiyama, A. Nishihara, C. Miki, H. Muta, M. Nakayama, and J. Takada, Human Resources Development with Information Technology: Simultaneous Satellite Lecture Provision for Tokyo Institute of Technology and Asian Institute of Technology, Regional Conference on Digital GMS, Vol. 1, pp. 313 317, Feb. 2003.

[3] A. Nishihara, International Distance Education at Tokyo Tech, ASEAN Engineering Journal, AUN/SEED-Net, Vol. 1, No. 2, pp. 31-39, Aug. 2011.

[4] A. Nishihara. Tokyo Tech Graduate Program Allied with Thailand: TAIST (Thailand Advance Institute of Science and Technology) - Tokyo Tech, IEEE EDUCON 2010, pp. 1031-1038, Apr. 2010.

[5] A. Nishihara, Y. Watanabe, Y. Kammei. Why We Should Use HighDefinition Video in Distance Education, ED-MEDIA 2009, AACE, pp. 1441-1446, Jun. 2009.

[6] J. Cao and A. NISHIHARA, Viewing behavior affected by slide features and learning style in slide video-From sequence analysis perspective, Japanese Society for Information and Systems in Education, Vol. 12, No. 1, Feb. 2014 